\title{
EL DEBATE CONSTITUCIONAL SOBRE EL DERECHO A LA EDUCACIÓN Y SU IMPACTO EN LA CIUDADANÍA*
}

\author{
The Constitutional Debate on the Right to Education and Its Impact on \\ Citizens
}

\section{CONSTANZA IHNEN}

Universidad de Chile

\section{SALVADOR MILLALEO}

Universidad de Chile

\section{FRANCISCO SOTO}

Universidad de Chile

\begin{abstract}
RESUMEN
En el contexto del actual proceso constituyente que vive Chile, la presente investigación ahonda en uno de los principales debates constitucionales que se desarrolla a lo largo de nuestra historia: el debate sobre el derecho a la educación. Analizamos este debate en un periodo acotado, de 1990 a 2016, con el fin de evidenciar cómo se relacionan los discursos de las élites y las opiniones ciudadanas. Con este objetivo proponemos, en primer lugar, una periodificación del debate de las élites, determinada por la irrupción del movimiento estudiantil del 2006 y 2011, y la paulatina constitucionalización de la discusión. En segundo lugar, recurrimos a un análisis discursivo de los diálogos ciudadanos, específicamente de los Encuentros Locales Auto-convocados (ELA) desarrollados en el marco del proceso constitucional que tuvo lugar en 2016. Finalmente, realizamos un ejercicio comparativo entre ambos para concluir que, si bien hay receptividad de las ideas de las élites en el discurso de los ELA, éste último no constituye un reflejo completo, cuestionando así la idea de que la ciudadanía sólo reafirma los discursos de la élite sin aportar nada nuevo.
\end{abstract}

Palabras clave: educación, reemplazo constitucional, movimientos sociales.

\begin{abstract}
In the context of the constituent process taking place in Chile, this paper studies one of the main constitutional debates that has developed throughout the country's history: the debate over the right to education. We analyse this debate between 1990 and 2016 to explore how elite discourse and citizens' opinions regarding the right to education are related. We first propose a periodization of the discussions of the elite, determined by the irruption of the Chilean student movement in 2006 and 2011, and the gradual constitutionalisation
\end{abstract}

Este trabajo fue parte del proyecto de investigación: “Hacia una teoría de la receptividad deliberativa en procesos constituyentes. Los diálogos ciudadanos en perspectiva comparada" (FONDECYT REGULAR $\left.\mathrm{N}^{\circ} 1170362\right)$. 
of the debate. We then carry out a discourse analysis of the citizen dialogues, specifically the Encuentros Locales Autoconvocados (ELA), or Self-convened Local Meetings, developed within the framework of the constitutional process that took place in 2016. Finally, by comparing both discourses, we conclude that although there is receptivity to the ideas of the elites in the ELA discourses, they do not constitute a complete reflection of these ideas. This questions the notion that citizen discourses only reaffirm the discourses of the elite without contributing anything new.

Keywords: education, constitutional replacement, social movements.

\section{INTRODUCCIÓN}

En el mundo y en Chile en particular, la opinión de la ciudadanía ha sido considerada marginalmente al momento de elaborar un texto constitucional. Los diálogos ciudadanos, realizados en el marco del "proceso constituyente abierto a la ciudadanía" que condujo el segundo gobierno de Bachelet en 2016, constituyeron un momento único donde los participantes pudieron deliberar sobre conceptos complejos, brindando argumentaciones públicas, las cuales pueden ser vinculadas con los debates que las élites políticas y los demás actores del debate público han tenido (Welp y Soto 2019).

Sin duda, uno de los objetos de debate y polémica política de las últimas décadas ha sido el derecho a la educación. Aunque las polémicas sobre la educación hunden su historia en el siglo XIX, en las últimas décadas se ha transformado en un eje que sirve para articular conjuntos muy complejos de diferencias políticas en nuestra sociedad (Peña 2015).

En este artículo nos proponemos describir los hilos comunes que han guiado los debates más importantes sobre el derecho a la educación, poniendo particular atención al modo en que se articulan el debate constitucional de élite y la deliberación desarrollada en el marco de los diálogos ciudadanos. En la descripción de los elementos comunes en estos debates, nos centramos en la capacidad de ciertas ideas -y los actores que las sustentan, con su poder ideacional- para estructurar los contenidos de las disputas por el significado del derecho a la educación.

Esta aproximación es novedosa ya que, pese a que numerosos estudios han analizado la relación entre los discursos de élite y las posiciones que adopta la ciudadanía en procesos de cambios constitucional, ninguno de ellos ha logrado profundizar en las interacciones que se generan en temáticas concretas y sólo llegan a caracterizaciones generales (Ghai 2006; Parlett 2012; Gluck y Ballou 2014; Saati 2015; Soto y Welp 2017). Por otra parte, algunos autores cuestionan la posibilidad de articular un real debate entre élite y ciudadanía a partir de un momento constituyente. La participación ciudadana operaría como una suerte de reafirmación de los discursos de la élite (Ackerman 1991), restringida a la elección de representantes o en la ratificación de un texto a 
través de referéndum. Así la deliberación ciudadana en procesos constituyente se acota a tres o cuatro experiencias puntuales y de impacto relativo (Welp y Soto 2019).

\section{PODER IDEACIONAL: IDEAS Y ACCIÓN COLECTIVA}

Existe una cotidiana oposición que se da entre las élites y los ciudadanos. Tras una larga historia de investigación (Mills 1956; Domhoff 1967; Putnam 1977; Bourdieu 1989; Hartmann 2006; Cousin et al. 2018), se puede comprender a las élites como el conjunto de "aquellos que tienen acceso a recursos en lugar de simplemente a aquellos que controlan recursos, donde individuos y grupos de interés pueden conectarse en red y dirigirse hacia una acción específica, para un resultado deseado" (Woods 1998: 2101). Las élites son conjuntos polimórficos de individuos vinculados por fuertes lazos sociales, políticos o profesionales que les permiten ejercer, y a través de los cuales ejercen, influencia de diferentes maneras, en variados ámbitos de la vida social.

Una cuestión relevante en el ejercicio del poder de las élites es la pregunta de cómo logran imponer o establecer determinadas ideas en la vida política, sobre todo en el contexto de la democracia moderna. La noción de "emprendimiento de políticas públicas" formulada en la ciencia política nos puede ayudar en ese propósito. Los "emprendedores de políticas públicas", inventan y divulgan soluciones a problemas públicos (Fischer y Forester 1993). Ellos son actores de índole especial que despliegan sus recursos y están atentos a las oportunidades para perseguir un cambio en un sector del proceso político, para cambiar las reglas de la política o para proveer bienes públicos. En ese sentido, podemos configurar como algún tipo de élite a todo actor que emprende consistentemente una lucha en pos de determinadas soluciones públicas, sea que correspondan a las élites socio-económicas con poder permanente en la sociedad o que ejerzan influencias de otro tipo, como el liderazgo cultural o la acción colectiva de partidos políticos y movimientos sociales.

Las ideas son las herramientas más poderosas de los emprendedores de políticas y éstos deben ser hábiles para construir narrativas en torno a un tema específico. En dichas narrativas definen los problemas de una manera que corresponde a la solución que promueven, conteniendo las motivaciones para el cambio a que aspiran. Las ideas interactúan con las instituciones para contribuir a los cambios de política, en términos de oportunidades creadas por eventos externos para avanzar una idea de política nueva o modificarla.

Las ideas pueden servir como una motivación individual para la acción, pero para funcionar como un vehículo para la acción colectiva y construcción de coaliciones, deben ser comunicadas como discursos entre las personas, a través de procesos de encuadre concretos y estratégicos. A través de procesos de encuadre, los actores presentan sus ideas, intentan conectar sus ideas a valores importantes y se esfuerzan por persuadir a otros de la validez de su interpre- 
tación particular de las ideas. Las ideas, cuando se combinan con el poder, funcionan como verdaderos "imanes de coalición" (Beland y Cox 2016: 2), construyendo alineaciones mediante una posición privilegiada sobre otras ideas en los debates y discusiones sobre políticas.

Los emprendedores políticos usan tanto su poder político como sus habilidades retóricas para crear imanes de coalición. Los emprendedores pueden ser de muchos tipos. En general, lo que hacen es utilizar su posición para abogar no solo por propuestas específicas, sino por la comprensión conceptual de problemas y cuestiones de política que legitiman y crean apoyo para sus propuestas (Beland y Cox 2016: 14).

El poder ideacional es la capacidad de los actores (ya sean individuales o colectivos) para crear coaliciones e influir en las creencias normativas y cognitivas de otros actores a través del uso de elementos ideacionales. Esto puede ocurrir directamente a través de la persuasión o imposición, o indirectamente al influir en el contexto conceptual que define el rango de posibilidades de los demás.

\section{EL DEBATE DE LAS ÉLITES SOBRE EL DERECHO A LA EDUCACIÓN}

Las discusiones en Chile sobre la educación, en su historia reciente, tomarán la forma que conocemos dentro del debate constitucional después de un prolongado proceso de desarrollo. En dicho proceso, podemos indicar que existen tres etapas, de acuerdo con el poder ideacional que ha sido desplegado detrás de las diversas posiciones: las ideas de los expertos y sus debates; las ideas de los movimientos sociales y sus luchas; y el discurso constitucional sobre el derecho a la educación.

\section{Primera etapa: Debate de Expertos, 2000-2006}

Las reformas curriculares de los gobiernos post-dictatoriales se enfrentaron a la crisis del sistema escolar buscando una reforma "desde arriba", sin amplia participación, con una validación y rol protagónico de expertos educacionales, aunque introduciendo algunos actores sociales en debates institucionalizados (Picazo 2013).

Es temprano el debate sobre los elementos que configuran el contenido normativo del derecho a la educación. UNICEF planteaba en el año 2000, que "concebir la educación como un derecho implica garantizar a cada niño y joven (independiente de su origen social, el nivel económico de su familia o su lugar de residencia) acceso y permanencia en la Educación Básica y Media (cobertura), niveles de aprendizaje satisfactorios (calidad) y un trato no discriminatorio, acorde con su dignidad humana (respeto)" (Bellei y Pérez 2000: 7). 
Las reformas de los 90' no promovieron cambios estructurales o institucionales en el sistema educativo diseñado en los 80' (Almonacid 2004) ni modificaron la distribución del gasto educativo (Cox 2005). La reforma intentaba una "tercera vía" consensual entre una restauración del rol estatal en la educación y la profundización del mercado (Picazo 2010; Bellei 2015).

A partir del año 2000, empezaron a abundar las críticas a la reforma educacional, en cuanto los sistemas de medición de la calidad de educación (SIMCE, PISA y otros) indicaron un estancamiento en los resultados en cuanto a la calidad de la educación (Bellei 2005: 34). Estas críticas empezaron a descomponer el consenso sobre la reforma y a sembrar distancias ideológicas sobre la educación. Estas cuestiones se ventilaban en los circuitos de la política y entre expertos, con la presencia solitaria del gremio de los profesores como actor no político-institucional dentro del debate y con la resonancia de los medios de comunicación masivos, que sostendrán desde entonces una "ácida crítica" al estado de la educación (Bellei 2015: 35). Dentro de dichas críticas se planteaba limitar o ajustar la libertad de enseñanza en términos de que ella no implique un proyecto de naturaleza excluyente (García-Huidobro 2004: 299).

\section{Segunda etapa: Movimientos Sociales, 2006-2013}

La situación del poder ideacional acerca de la educación se va a alterar sustancialmente con la irrupción de los movimientos sociales como nuevos emprendedores políticos en educación. A diferencia de los actores gremiales, como los sindicatos de profesores, éstos reformularán las demandas al sistema educativo con claridad desde una reinterpretación de los contenidos del derecho a la educación de calidad, cuestionando los fundamentos del sistema educativo (Insunza 2009: 103).

Las formulaciones discursivas del movimiento estudiantil se irán desarrollando para cristalizar en la principal crítica contra las políticas sociales y económicas neoliberales en Chile, ante sus resultados en altos grados de desigualdad entre una minoría privilegiada y la mayoría de la población (Bellei y Cabalin 2013: 112) y a favor de una democracia más inclusiva (Donoso 2013).

El discurso de los estudiantes secundarios en 2006, en la rebelión de los pingüinos, en el primer año del primer gobierno de Bachelet (2006-2010), puso en cuestión el sistema educativo como un todo e identificó los problemas de la educación en las características arquitectónicas que había establecido la dictadura para ella, criticando a su vez su continuidad en democracia (Donoso 2013: 2). Sostenían un juicio crítico respecto a las políticas educacionales de la Concertación, en cuanto habían fallado en generar mayor equidad, puesto que mientras más estudiantes que nunca concluían su educación secundaria, había diferencias en la calidad ofrecida por las tres categorías de instituciones del sistema, cargadas de consecuencias para su futuro en la educación superior y en las oportunidades que ésta abría (Cox 2012; Bellei y Cabalin 2013). La expansión de la cober- 
tura favorecía la educación privada a expensas de la educación pública y se abría una segregación social en la calidad de la educación (Treviño et al. 2014).

Los estudiantes secundarios, en alianza con otros movimientos sociales (Bloque Social por la Educación), docentes (Colegio de Profesores) y centros de estudios como CENDA y OPECH, comprendían el derecho a la educación como el derecho a un bien social público, de índole laica, multi- e intercultural, con infraestructura de calidad, sin ningún tipo de discriminación económica, social, cultural, ideológica, de género, étnica de minorías con necesidades educativas especiales y diferentes opciones sexuales. El Estado debía promover un proyecto educativo ciudadano que respondiese a las necesidades de la transformación social y desarrollo nacional, y no solo a los requerimientos del mercado o los proyectos de algunos sectores corporativos. Para ello requerían una reforma constitucional que otorgara prevalencia al derecho a la educación de calidad integral y a la participación en primer lugar, por sobre el derecho a la propiedad, a la libre empresa y a la libertad de enseñanza.

El Consejo Asesor Presidencial creado en 2006 hizo varias propuestas para fortalecer el derecho a la educación pública y de calidad. El Consejo reconoció como fundamento de sus propuestas que había una asimetría entre la libertad de enseñanza y el derecho a la educación, careciendo el último de garantías (Consejo Asesor 2006: 63), sugiriendo instituir un derecho fundamental a una educación gratuita de calidad (Consejo Asesor 2006: 64).

El primer gobierno de Bachelet recogió algunas de las propuestas del Consejo e impulsó el reemplazo de la LOCE por la Ley General de Educación (LEGE), Ley N $N^{\circ} 20.370$ de 2009. La Ley N²0.129, que establece un Sistema Nacional de Aseguramiento de la Calidad de la Educación Superior fue aprobada en 2006. El resultado fue una reforma "basada en estándares", es decir, la definición de estándares respecto de los procesos de aprendizaje y de los procesos institucionales, supervigilados por una superintendencia de educación y certificados por agencias de calidad (Bellei 2015). La construcción de un sistema de Aseguramiento de la Calidad en este período significará la consolidación del Estado evaluador.

La mantención del predominio de agentes privados y de las prácticas de selección en la educación media, así como la no afectación del sistema de educación superior, supondrán las bases de un nuevo movimiento de protesta desde 2011. El sistema escolar seguía estando fundado en el mercado y la competencia, con cuatro rasgos principales: "i) la construcción de un sistema mixto en términos de su propiedad, con un fuerte desarrollo del sector privado; ii) la consolidación de un sistema de financiamiento basado en el subsidio a la demanda; iii) la institucionalización del lucro y el copago como mecanismos de organización del sistema; y iv) la generación y desarrollo de importantes incentivos y castigos a escuelas, docentes y estudiantes" (Villalobos y Quaresma 2015: 69). 
El lucro, en particular, se refiere a quien toma las decisiones claves que afectan el derecho a la educación de calidad de los niños y jóvenes, esto es, a los propietarios y administradores de los establecimientos educacionales (Bellei 2011), introduciendo la lógica de la privatización al interior de las escuelas y establecimientos, como un reflejo de la mercantilización de la vida cotidiana (Orellana 2012).

Hay que resaltar que en esta etapa se mantiene sustantivamente una continuidad subyacente en orientaciones de las políticas educativas, el llamado manual invisible (Salazar y Leihy 2013). Esta comprensión seguía enfatizando el rol de la regulación para alcanzar una coordinación más balanceada del sector educativo, combinando autonomía de los proveedores y accountability.

En las movilizaciones estudiantiles que se han suscitado desde 2011, en el llamado Invierno Chileno, los principales protagonistas han sido los estudiantes universitarios. Estas movilizaciones han sido explicadas, por algunos -Eugenio Tironi y Carlos Peña- como una crisis de expectativas con respecto a la movilidad social y más aún a la defensa de un tipo de sociedad mayormente meritocrática (Azocar 2014: 209); por otros -Garretón- como consecuencia del proceso de privatización y mercantilización de la vida social del modelo de desarrollo chileno, y en específico como un rechazo a dicha mercantilización o a la desigualdad en el reparto de oportunidades (Azócar 2014: 210). Para otros -Mayol, Salazar, Grez- las movilizaciones también involucrarían una respuesta a la falta de legitimidad que tendría el sistema político chileno en su conjunto. Un factor inmediato a las movilizaciones, referido por uno de los líderes del movimiento estudiantil, fue el alto nivel de endeudamiento que los estudiantes tenían con el sistema financiero, con créditos con altos intereses, mediante el mecanismo del crédito con aval del Estado (CAE) (Jackson 2013: 61).

Para Fernández Labbé, una de las características singularizadoras de las movilizaciones estudiantiles de 2011, fue su capacidad para generar propuestas políticas (2016: 177).

El movimiento estudiantil de 2011 transformó al derecho a la educación en un derecho comprendido, en primer lugar, como un derecho social, al cual se había dotado de legitimidad social en las calles, en los cacerolazos, logrando sensibilidad social y visibilidad mediática dentro y fuera del país. La diferencia fundamental fue en el énfasis en la educación superior y las actividades de universidades y otras instituciones privadas de educación superior que perseguían fines de lucro.

Pese a las descripciones anteriores, hay que resaltar que los movimientos sociales y los expertos que han apoyado o complementado sus posturas no han encontrado un consenso en los debates sobre educación. Según Bellei, ha sido una característica del debate sobre educación "la falta de convergencia sobre sus alcances, contenidos y énfasis" (Bellei et al. 2010: 13). 
Sin embargo, hay que resaltar que las formas de acción de los movimientos sociales difieren de aquella de los expertos por sí solos, en cuanto los primeros son actores colectivos que intermedian marcos de significado desde la ciudadanía hacia los centros de toma de decisión. Por ello tienen mayor capacidad de injerencia pública que los expertos, aunque menos estabilidad que ellos. Ahora bien, los movimientos estudiantiles en Chile se han caracterizado por ser actores acompañados por expertos, desde el principio y hasta ahora (Acuña 2016).

\section{Tercera Etapa: Constitucionalización del Debate, 2013-2017}

El segundo gobierno de Bachelet incorporó en su programa tanto un cambio estructural del sistema educativo -realizando diversas reformas (Leyes $\mathrm{N}^{\circ}$ $20.835,20.845,21.040,21.091)$, que tomaban varias banderas del movimiento estudiantil para construir una nueva educación pública (Treviño 2018; Villalobos et al. 2019)- como la convocatoria a un proceso constituyente para generar una nueva constitución. Ambos temas están íntimamente vinculados a partir de las demandas del movimiento estudiantil.

En esta etapa, los expertos constitucionales, en cooperación con movimientos sociales, actúan como emprendedores de una transformación política cuando traducen las discusiones entre expertos, actores gremiales, y movimientos sociales, en discursos de derecho constitucional. Su poder ideacional será resistido por otros discursos constitucionales, con apoyo de actores gremiales y asociaciones de padres y apoderados (Confederación de Padres y Apoderados de Colegios Particulares Subvencionados).

\section{a) La Educación y Libertad de Enseñanza frente a frente}

La libertad de enseñanza, en su comprensión tradicional y dominante en las cortes de justicia, será presentada como un derecho diferente, correlato antes que un instrumento del derecho a la educación, así como de la protección de la familia en el cumplimiento de las funciones que le son inherentes en relación con los hijos (Cea 2013: 349).

El núcleo de la libertad de enseñanza, desde una visión de derechas, José Luis Cea lo ha definido como el derecho a participar en la transmisión metódica de información y conocimiento a los estudiantes del sector público o privado, en cualquiera de sus niveles (Cea 2013: 365). Dicha libertad comprende abrir, fundar o establecer; organizar, dirigir o regir; mantener, desarrollar o cerrar establecimientos educacionales (Cea 2013: 366). Los únicos límites externos que admite la Constitución son la moral, las buenas costumbres, el orden público y la seguridad nacional.

Desde su origen esta concepción se orientó por la subsidiaridad de la intervención estatal. Esta subsidiaridad favorecía la participación del sector privado en la educación, reservándose al Estado funciones normativas, técnico-peda- 
gógicas y de supervisión (San Francisco 1992: 534). La comisión redactora de la Constitución de 1980 descartó la concepción del Estado Docente (San Francisco 1992: 537), a favor del protagonismo privado, el cual era protegido por la libertad de enseñanza, donde el Estado tiende a ser pasivo (San Francisco 1992: 538). La libertad de enseñanza es correlato del derecho a la educación, en cuanto la función educativa (y deber de ejercerla) corresponde a los padres primordialmente, pudiendo, como sostuvo Jaime Guzmán, colaborar a ella los privados que lo deseen. El Estado debe proteger y respetar el ejercicio de este derecho, y es en su función educativa, subsidiario a las familias y los privados (San Francisco 1992: 539).

Siguiendo esa línea, algunos juristas de la derecha se han opuesto a priorizar el derecho a la educación por sobre la libertad de enseñanza, en cuanto serían derechos diferenciados y equivalentes, debiendo darse la relación entre uno y otro en un test de balance o proporcionalidad (Vivanco 2007: 2).

\section{b) "Otro" Derecho a la Educación}

La comprensión tradicional de la relación entre derecho a la educación y la libertad de enseñanza será cuestionada. Desde las izquierdas se llegará a plantear que el régimen de lo público implica, en lugar de la propiedad, el tratamiento debido que les da el Estado a los usuarios, en tanto los considera ciudadanos antes que clientes. La provisión privada de bienes públicos no es problemática si es que no se opone a los intereses del ciudadano y si se oponen, debe preferir ineludiblemente a los ciudadanos (Atria et al. 2013). El lucro precisamente amenaza el interés público puesto que estimula a que los prestadores privados de servicios o bienes públicos restrinjan los gastos de dicha provisión para obtener más beneficios. Esta contradicción puede ser satisfecha en otros ámbitos de lo público mediante la regulación que fija estándares mínimos ex ante, pero esto es imposible en la educación, donde debe proveerse el mejor servicio posible con los recursos, de manera que no puede resolverse la contradicción potencial entre el interés privado al lucro y el interés público, debiendo excluirse la persecución del lucro como una actividad legítima dentro de la provisión de educación (Atria et al. 2013: 202). La provisión privada de bienes públicos sólo será legítima si los privados están en la misma posición respecto a los usuarios que el Estado, esto es, cuando los trata como ciudadanos y no como clientes.

En esta visión, el derecho a la educación debe ser comprendido como un derecho social a la ciudadanía, antes que como un derecho a prestaciones mínimas. Atria sostiene que la condición de derecho social implica el deber del proveedor de servicios de educación de proveer (DS2), determinando que el proveedor -en cuanto la provisión no sirve su propio interés sino el interés del ciudadano (DS1) - no está en condiciones de establecer, unilateralmente, condiciones especiales de provisión caso a caso, sino que las condiciones de acceso se deben fijar en un protocolo público aplicable a todos por igual (DS3) (Atria 2014: 128). 
Lo anterior implica un régimen público que debe excluir la posibilidad de que establecimientos públicos tengan proyectos educativos que respondan a intereses particulares, y el reconocimiento del igual derecho de todos los ciudadanos a ingresar a cualquier establecimiento escolar, excluyendo cualquier forma de selección (Atria 2014: 224). También involucra la exclusión de todo pago a cambio de un servicio educativo, esto es, el llamado copago o financiamiento compartido (Atria 2014: 227). La gratuidad de la educación superior también es un reflejo de la descomodificación de la comprensión de la educación, y su enfoque como un derecho social universal (Atria 2014: 232).

Atria había planteado desde mucho antes que el significado de la educación pública estaría dado por la naturaleza del derecho que ella satisface, esto es, un derecho universal a la educación como una necesidad de la construcción de una ciudadanía común (2010).

\section{c) El Derecho a la Educación como regulación: De nuevo la Libertad de} Enseñanza

Otros han indicado que la libertad de enseñanza y el derecho a la educación pueden articularse a través del incremento de las capacidades y ámbitos de regulación del Estado para garantizar el derecho a la educación, en lugar de reconfigurar a la libertad de enseñanza como un instrumento de la educación, como, según cuestionan, la reforma educacional del segundo gobierno de Bachelet pretendía hacer.

El constitucionalista vinculado al centro político, Pablo Ruiz-Tagle ha apuntado a la carencia de instrumentos que permitan al Estado garantizar el derecho a la educación (Ruiz-Tagle 2010: 34). Para ello ha propuesto la regulación legal de un sistema más fuerte de fiscalización para la educación pública y privada. Para Ruiz-Tagle, una reforma deberá garantizar el desarrollo de la educación particular, para lo cual es necesario establecer condiciones de funcionamiento de los establecimientos educacionales que aseguren la seriedad de la empresa educativa y la calidad de la enseñanza impartida. Destaca también la conexión que tiene este derecho con la política.

Larroulet y Gorosabel (2015), desde las derechas, buscarán un regreso a los grandes acuerdos en las políticas educacionales de los gobiernos de la Concertación, es decir, proponiendo restaurar la comprensión subsidiaria de la relación entre derecho a la educación y libertad de enseñanza y procurar, de esa forma, desconstitucionalizar el debate, retrotrayéndolo a la discusión de políticas públicas. Ellos señalan como prioridades políticas el fortalecimiento de la educación preescolar, la mejora de la calidad de la educación escolar, el aseguramiento de calidad de educación superior, y la ampliación de cobertura y calidad en la educación para el trabajo (técnico-profesional) (Larroulet y Gorosabel 2015: 81). Fortalecer la educación pública no significaría aquí desconocer, sino reconocer y proteger la diversidad entre los proyectos educativos a través de la libertad de enseñanza. En estos sentidos, el derecho a la educación 
no sería incompatible con la existencia de un régimen de mercado educacional (Larroulet y Gorosabel 2015: 130).

\section{EL DERECHO A LA EDUCACIÓN EN LOS ENCUENTROS LOCALES AUTOCONVOCADOS}

El objetivo de esta sección consiste en describir los contenidos normativos atribuidos al derecho a la educación por parte de la ciudadanía que participó en los ELA, desarrollados en 2016, en el marco del proceso constitucional que tuvo lugar en el segundo gobierno de Bachelet. Dicha descripción se basa en una sistematización propia, distinta a la propuesta por el Comité de Sistematización convocado por el gobierno.

\section{Los Encuentros Locales Autoconvocados y su Sistematización}

Los ELA fueron grupos organizados por la propia ciudadanía, con no menos de 10 ni más de 15 integrantes que se reunían con el objetivo de discutir los temas propuestos en la convocatoria. Finalizados los encuentros, los participantes debían completar un formulario compuesto de preguntas estructuradas y cerradas y otra sección de preguntas abiertas. Las preguntas cerradas se organizaron en 4 ejes temáticos: "Valores", "Derechos", "Deberes" e "Instituciones." En el formulario se buscaba que los participantes respondieran, por ejemplo, “¿Cuáles son los derechos más importantes que la Constitución debiera establecer para todas las personas?", y así sucesivamente se consultaba por valores y principios, deberes e instituciones. Los participantes debían priorizar para cada eje temático 7 conceptos. La sección de preguntas abiertas constó de dos partes: una para señalar los "fundamentos" del grupo para optar por cada una de sus 7 preferencias en cada uno de los ejes temáticos consultados y otra que permitía dar un testimonio final de la experiencia vivida en la consulta.

En enero de 2017, el Comité de Sistematización publicó un informe ejecutivo titulado "Sistematización de la Etapa Participativa del proceso Constituyente abierto a la ciudadanía" (2017) y que daba cuenta de los conceptos más tratados en las diversas instancias del proceso participativo y de las ideas fuerzas que en cada caso describen los fundamentos principales consignados en los formularios.

La sistematización de los "fundamentos" consistió en un análisis de contenido cuantitativo, cuya unidad de registro fueron las palabras, guiado por un principio interpretativo literal y codificado en base a categorías creadas inductivamente. La frecuencia de palabras se contabilizó teniendo en consideración la función gramatical desempeñada (sustantivo, verbos y atributos), dentro de lo que se denominó un "modo argumentativo" determinado (fáctico, valorativo y propositivo) para cada concepto analizado (por ejemplo, el derecho a la edu- 
cación). A partir de ese análisis de frecuencias se propusieron "ideas fuerzas" para cada "modo argumentativo" y una idea fuerza general con función de síntesis.

Según el documento Encuentros Locales Autoconvocados preparado por el Comité (2016: 4), una idea fuerza es "una composición que busca caracterizar de manera breve el conjunto de los fundamentos a partir de las expresiones [palabras] que mayoritariamente aparecen en ella." Esta frase "no corresponde a un fundamento efectivamente consignado en un acta", sino que proviene de la agregación de las palabras que registraron mayor frecuencia. Así, la idea fuerza general consignada en el citado documento para el derecho a la educación fue la siguiente (Comité de Sistematización 2016: 7):

Idea fuerza: Se describe como un derecho social y humano, fundamental. Se vincula principalmente a las aspiraciones de una educación de calidad, gratuita, pública y universal. Se valora por la posibilidad que brinda para generar, desarrollar o permitir el desarrollo del país, la sociedad en igualdad de derechos y oportunidades. Se propone fundamentalmente la necesidad de que haya una educación de calidad, gratuita y pública. También se menciona la aspiración de una educación digna, laica, integral y sin lucro.

Por su parte, las ideas fuerzas consignadas para cada modo argumentativo fueron presentadas mediante la tabla 1, extraída del mismo documento (Comité de Sistematización 2016: 7).

No obstante contar con estos resultados, hemos decidido desarrollar una sistematización alternativa de los "fundamentos", por dos razones.

En primer lugar, porque el objetivo buscado por el Comité fue solamente "sistematizar de manera descriptiva los resultados de la participación ciudadana" (Comité de Sistematización 2016: 4), en circunstancias que también es necesario para nosotros lograr una descripción que aporte información contrastable con el discurso de las élites. Es natural que propósitos de investigación diversos requieran la formulación de categorías de análisis de discurso también diversos.

En segundo lugar, porque la sistematización aportada por el Comité presenta, desde nuestra perspectiva, debilidades metodológicas, posiblemente atribuibles a los plazos poco realistas fijados por el gobierno para la publicación de los resultados. La primera debilidad se sigue de la decisión de interpretar literalmente los enunciados, basándose en frecuencia de palabras, en circunstancias que "describir" el contenido de un discurso requiere ser lo más fiel posible a la intención comunicativa de los participantes, lo cual se consigue con un análisis pragmático cuya unidad de registro sean los enunciados.

La segunda debilidad dice relación con el procedimiento de agregación de palabras utilizado para construir las llamadas "ideas fuerzas." El proceso de sistematización consistió en desagregar los componentes de los enunciados 
Tabla 1. Derecho a la educación: ideas fuerzas y modos argumentativos.

\begin{tabular}{|c|c|c|c|}
\hline \multirow{2}{*}{$\begin{array}{c}\text { Actitudes } \\
\text { Argumentativas } \\
\text { o modo* }\end{array}$} & \multicolumn{2}{|c|}{ ¿Qué se dijo?** } & \multirow{2}{*}{$\begin{array}{l}\text { Idea fuerza } \\
\text { del modo*** }\end{array}$} \\
\hline & Conceptos o acciones fuente & $\begin{array}{l}\text { Atributos o conceptos } \\
\text { vinculados }\end{array}$ & \\
\hline $\begin{array}{l}\text { ¿Qué es? } \\
\text { Modo fáctico } \\
16,2 \%\end{array}$ & 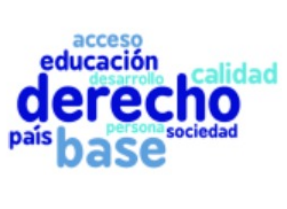 & 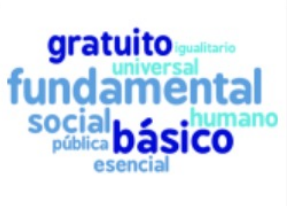 & $\begin{array}{l}\text { Se describe como un derecho } \\
(25 \%) \text { social }(7 \%) \text { y humano }(8 \%) \text {, } \\
\text { fundamental (20\%). Se vincula } \\
\text { principalmente a las aspiraciones } \\
\text { de una educación }(8 \%) \text { de calidad } \\
(6 \%) \text {, gratuita }(8 \%) \text {, pública }(2 \%) \text { y } \\
\text { universal }(3 \%) \text {. }\end{array}$ \\
\hline $\begin{array}{c}\text { ¿Qué valor tiene? } \\
\text { Modo valorativo } \\
5,1 \%\end{array}$ & $\begin{array}{l}\text { generar lograr } \\
\text { construir } \\
\text { deSalparar } \\
\text { ser perzar itir }\end{array}$ & $\begin{array}{l}\text { calidad } \\
\text { derecho pals igualdad } \\
\text { desarrollo vida } \\
\text { sociedad }\end{array}$ & $\begin{array}{l}\text { Se valora por la posibilidad que } \\
\text { brinda para generar, desarrollar } \\
(5 \%) \text { o permitir }(5 \%) \text { el desarrollo } \\
(13 \%) \text { del país }(6 \%) \text {, la sociedad } \\
(10 \%) \text { en igualdad }(3 \%) \text { de } \\
\text { derechos }(3 \%) \text { y de oportunidades } \\
(3 \%) \text {. }\end{array}$ \\
\hline $\begin{array}{c}\text { ¿Qué hacer? } \\
\text { Modo propositivo } \\
76,4 \%\end{array}$ & $\begin{array}{l}\text { derécho } \\
\text { acceso } \\
\text { educación }\end{array}$ & $\begin{array}{l}\text { social laico integral } \\
\text { digno } \text { Uublico }_{\text {universal }}^{\text {gratis }}\end{array}$ & $\begin{array}{l}\text { Se propone fundamentalmente la } \\
\text { necesidad de que haya una } \\
\text { educación }(26 \%) \text { de calidad (27\%), } \\
\text { gratuita (33\%) y pública (11\%). } \\
\text { También se menciona la aspiración } \\
\text { de una educación laica }(5 \%) \text {, digna } \\
(3 \%) \text {, integral }(3 \%) \text {, con acceso } \\
(7 \%) \text {, inclusiva }(2 \%) \text {, sin lucro (1\%). }\end{array}$ \\
\hline \multicolumn{4}{|c|}{$\begin{array}{l}\text { "El cálculo de los porcentajes no considera las menciones categorizadas "inclasificables". Los porcentajes no suman } 100 \% \text { por que solo se rescatan las "Actitudes } \\
\text { Argumentativas" con mayores frecuencias. } \\
\text { "** En esta columna se muestran los conceptos o acciones fuente y atributos más frecuentes dentro de los sintagmas de objeto de las oraciones. En el caso del } \\
\text { modo valorativo se muestran los verbos en infinitivo y lo sustantivos más frecuentes en los complementos de las oraciones. El número de menciones y } \\
\text { porcentajes están consignados a continuación en "Frecuencia de palabras". } \\
\text { *** Los porcentajes están calculados sobre el total de "conceptos o acciones fuente" o "atributos o conceptos vinculados" de cada modo según corresponda } \\
\text { (ver frecuencia de palabras). Los porcentajes están aproximados al entero más cercano. }\end{array}$} \\
\hline
\end{tabular}

contenidos en los fundamentos, categorizarlos gramaticalmente y "argumentativamente", para luego agregarlos en un enunciado ficticio -en el sentido de que no es un enunciado consignado en las actas-, que recoge las palabras y sus frecuencias. Nos parece que esta forma de proceder puede distorsionar el sentido de lo comunicado. Por ejemplo, para el derecho a la educación se señala como idea fuerza del modo argumentativo valorativo (columna 3, fila 2 de la tabla 1): el derecho a la educación "se valora por la posibilidad que brinda para [...] el desarrollo (13\%) del país (6\%), la sociedad $(10 \%)$ en igualdad $(3 \%)$ de derechos $(3 \%)$ y de oportunidades (3\%)."

Esta idea fuerza pudiese estar distorsionando lo comunicado por los encuentros locales en dos sentidos. Primero, porque la idea fuerza no indica realmente la frecuencia con que se valora el derecho a la educación por la posibilidad que brinda para el desarrollo del país y la sociedad, sino, simplemente, la frecuencia con que se utilizaron las palabras "desarrollo", "país" y "sociedad" en la misma función gramatical (sustantiva) dentro del mismo modo argumentativo (valorativo): $13 \%, 6 \%$ y 10\% respectivamente. Dichas palabras pudieron haber sido usadas en un contexto enunciativo diverso a la idea fuerza propuesta. Por ejemplo: "desarrollo" pudo utilizarse en el enunciado "Se valora por la 
posibilidad que brinda para el desarrollo de la persona." Coincidentemente, "persona" está entre los sustantivos mencionados en el modo valorativo para este derecho -según consigna el análisis de frecuencia de palabras publicado en el mismo informe (Comité de Sistematización 2016: 8). Lo anterior nos lleva al segundo problema que observamos en relación con la formulación de las ideas fuerzas: se supone que se construyen a partir de las palabras que "mayoritariamente" aparecen en determinada función gramatical en el contexto de un modo argumentativo. Sin embargo, la misma palabra "persona" tiene, en la función gramatical de sustantivo, y en el contexto del modo valorativo, un 6\% de menciones. ¿Qué explica, por ejemplo, que ésta no aparezca en la idea fuerza del modo valorativo y sí aparezca en cambio "sociedad" (6\%), "en igualdad" $(3 \%)$, "derechos" (3\%) y "oportunidades" $(3 \%)$ ?

\section{Propuesta Metodológica para una Sistematización Alternativa}

La educación fue el derecho con mayor número de menciones en los ELA: 5,562 encuentros lo mencionan como uno de los 7 derechos más importantes que debe establecer la Constitución. ${ }^{1}$ De ese total, 5,291 encuentros consignaron acuerdo total en los fundamentos. ${ }^{2}$ Nuestro universo corresponde a esos 5,291 ELA en los que se consignó acuerdo.

A la luz de nuestros objetivos -interpretar fielmente los diálogos ciudadanos y comparar los contenidos normativos allí propuestos con los del debate de la élite- desarrollamos una metodología basada en tres principios:

1. Interpretación pragmática de los fundamentos: para ser lo más fiel posible a los significados atribuidos por los participantes de los diálogos a su discurso, optamos por un análisis pragmático del discurso en los fundamentos de los ELA. Esta perspectiva pragmática implica que: i) la unidad mínima de significado es el enunciado en contexto, y que, por lo tanto, nuestra unidad de análisis no son las palabras sino los enunciados; ii) el significado de un enunciado puede manifestarse en el lenguaje natural de forma explícita (literal y directa) o implícita (no literal o indirecta) y, que por ende, nuestro análisis de los fundamentos deberá incluir necesariamente la reconstrucción de significados implícitos; y iii) para determinar el significado de un enunciado es necesario no sólo identificar el contenido proposicional del enunciado (o "acto locutivo"), compuesto de sujeto, predicado y sus determinantes, sino también identificar el acto de habla (o "acto ilocutivo") que se realiza mediante el enunciado. Así, además de determinar el contenido de los enunciados en cada uno de los fundamentos, determinamos también el acto de habla que se realiza mediante él. Los actos de habla identificados

La base de datos utilizada para nuestra investigación fue descargada de www.sistematizaciónconstitucional.cl el 19/08/2016.

Los participantes debían indicar el nivel de acuerdo que le asignaron al derecho a la educación: acuerdo total, acuerdo parcial o desacuerdo. 
en los encuentros fueron de dos tipos: el acto de habla de presentar un punto de vista en torno al derecho a la educación (y en particular a sus contenidos normativos) y el acto de habla de argumentar, es decir, de justificar ese punto de vista.

2. Análisis de contenido de tipo cualitativo y cuantitativo: precisamente porque nuestra perspectiva es pragmática, realizamos primero un análisis cualitativo en la reconstrucción de enunciados y su significado. Esto nos permite establecer cuáles son los contenidos normativos del derecho a la educación tematizados en los encuentros. Pero también realizamos un análisis cuantitativo al registrar la frecuencia de cada una de estas categorías de enunciados. Esto nos permite definir con qué énfasis aparecen ciertos temas.

3. Construcción inductiva y deductiva de las categorías de análisis del discurso: El carácter abierto de la pregunta formulada en las actas para registrar los fundamentos de los ELA implica que para construir categorías de codificación sea necesario aprender del material y, por ende, construir categorías inductivamente. Sin embargo, resulta también fundamental para nuestros objetivos interpretar los encuentros de manera de poder extraer información relevante y comparable con el discurso de las élites. En consecuencia, luego de haber propuesto una tabla de categorías inductivas, hemos optado además por reorganizar las categorías con técnicas deductivas, es decir, iluminadas por el debate de élite en torno al derecho a la educación. ${ }^{3}$

Nuestra metodología constó de 4 etapas que pasamos a detallar a continuación.

\section{a) Definición del Objeto de Análisis}

El objeto de análisis se define conforme a la unidad de muestreo, de registro y de contexto. La unidad de muestreo fueron los fundamentos de los 5,291 ELA en los que se escogió la educación como uno de los derechos más importantes que debía consagrar la Constitución y en los que se consignó acuerdo. Es decir, no se conformó una muestra propiamente tal, sino que se analizó el universo completo de fundamentos consignados en los 5,291 ELA. La unidad de registro es aquella parte de la unidad de muestreo que se caracteriza al situarlo en una categoría dada. Nuestra unidad de registro son los puntos de vista en torno al derecho a la educación expresados mediante enunciados en los ELA. Dejamos fuera de nuestro análisis los enunciados con función argumentativa. Esta decisión obedece meramente a razones de tiempo. Nuestra unidad de contexto para la interpretación de las unidades de registro fue cada ELA contenido en la unidad de muestreo.

Un ejemplo en esta línea es el concepto de "derecho social". Una mirada meramente inductiva constataría que las palabras "derecho" y "social" se repiten con considerable frecuencia y construirá estas dos categorías de forma separada. Una mirada orientada desde la teoría constitucional construirá la categoría "derecho social" para observar cuántas veces "social" determina a "derecho." 


\section{b) Construcción de categorías o "puntos-de-vista-tipo"}

Luego se procedió a la construcción de las categorías en las que serían clasificados cada uno de los puntos de vista extraíbles de los fundamentos. Debido a nuestra aproximación pragmática, nuestras categorías de análisis no son conceptos, sino "puntos-de-vista-tipo."

El conjunto de puntos-de-vista-tipo comprende un punto-de-vista-tipo mínimo atribuible a toda nuestra muestra y un conjunto de puntos-de-vista-tipo más complejos. El punto-de-vista-tipo mínimo atribuible es: "La Constitución debe establecer el derecho a la educación." Los puntos-de-vista-tipo complejos, pueden serlo en diversos grados, dependiendo de la cantidad de información adicional que se añada al punto-de-vista-tipo mínimo. Por ejemplo, el fundamento "La Constitución debe establecer el derecho a la educación de calidad", es una manifestación compleja del punto-de-vista-tipo mínimo, pues agrega información al especificar que el derecho a la educación debe ser de calidad.

También se construyeron categorías de sub-puntos-de-vista-tipo. Los sub-puntos de vista son puntos de vista en los que, además de especificarse un atributo para el derecho a la educación, aparece un complemento o sintagma que determina al atributo. Un ejemplo es el siguiente: "La Constitución debe establecer el derecho a la educación gratuita focalizada en quienes más lo necesitan", donde "gratuita" es el atributo de "derecho a la educación" y las palabras en cursivas representan el sub-punto de vista en relación a la gratuidad de la educación.

\section{c) Codificación}

La codificación consistió en asignar para cada fundamento un código qué indicaba el o los (sub)puntos-de-vista-tipo identificados en dicho fundamento. Esta etapa fue necesaria para automatizar el análisis cuantitativo. Tanto la construcción de categorías como la codificación se hicieron manualmente, con el apoyo de un equipo de 10 ayudantes, supervisados y formados en talleres de análisis pragmático de fundamentos. Con el objeto de asegurar la fiabilidad de resultados, dos analistas codificaron de forma independiente un mismo conjunto de unidades de registro. Las discrepancias obtenidas alcanzaron 487 (9.2\%) cambios de códigos mientras que las concurrencias llegaron hasta 4,804, lo que establece un nivel de fiabilidad de $90.8 \%$.

\section{d) Análisis Cualitativo y Cuantitativo}

El análisis cualitativo nos permitió establecer catálogos con los puntos-de-vista-tipo y sub-puntos-de-vista-tipo presentes en la muestra. El análisis cuantitativo consistió en el registro de frecuencias de puntos-de-vista-tipo (tablas 2, 3 y 4) y sub-puntos-de-vista-tipo (tablas 5, 6, 7, 8, 9 y 10) junto a sus porcentajes. Los catálogos son exhaustivos de los puntos-de-vista-tipo y sub-puntos-de-vista-tipo presentes en la muestra. 
En cuanto al análisis cuantitativo, los porcentajes asignados a cada categoría del catálogo de puntos-de-vista-tipo (tablas 2-4) se obtuvieron a partir del número de veces que se manifestó un punto-de-vista-tipo en relación al total de puntos de vista extraídos de la muestra (5,387 puntos de vista). Los porcentajes asignados a los sub-puntos-de-vista-tipo (tablas 5-10) se calcularon de dos formas, dependiendo de si los sub-puntos-de-vista-tipo eran categorías excluyentes o no. Cuando las categorías de sub-puntos-de-vista-tipo eran excluyentes, los porcentajes se calcularon a partir del total de menciones del punto-de-vista-tipo al que estaban asociados los sub-puntos-de-vista. En cambio, cuando las categorías de sub-puntos-de-vista-tipo eran no-excluyentes, el porcentaje de frecuencia se calculó sobre la base del número de ocurrencias de los subpuntos-de-vista-tipo.

\section{Resultados de la Sistematización Alternativa}

Del total de 5,387 puntos de vista extraídos de la muestra, 1,082 de ellos $(20.09 \%)$, son clasificables bajo el punto-de-vista-tipo mínimo atribuible a los ELA: a saber, "La CPR debe establecer el derecho a la educación." Los 4,305 puntos de vista restantes (79.91\%), además de comprometerse con la afirmación anterior, atribuyen contenidos normativos al derecho a la educación.

Estos 4,305 puntos de vista son analizables en términos de puntos-de-vista-tipo con diversos grados de complejidad. Mientras más complejo el nivel de análisis (mientras más atributos contenga una categoría), más difícil de procesar resulta la información y, por ende, más limitadas serán las conclusiones generales que podremos obtener de los resultados. En vista de ello optamos por analizar la mayoría de los puntos de vista en términos de puntos-de-vista-tipo donde se agrega 1 sólo atributo al punto-de-vista-tipo mínimo y construir sólo un grupo pequeño de categorías correspondientes a puntos-de-vista-tipo más complejos, esto es, con más de un atributo, con el objeto de investigar asociaciones específicas entre atributos.

La tabla 2 contiene un catálogo de puntos-de vista-tipo complejos, en los que la educación aparece determinada por un solo atributo. Los puntos-de-vista-tipo se ordenan de mayor a menor frecuencia. En definitiva, la tabla 2 ofrece información sobre cuáles son los contenidos normativos que los participantes de los ELA atribuyen al derecho a la educación y con qué fuerza. ${ }^{4}$

\footnotetext{
Para la correcta lectura de las frecuencias, es importante enfatizar que las frecuencias en la tabla 2 no representan el número de puntos de vista complejos en los que se mencionó sólo un atributo determinado, sino el número de puntos de vista complejos que incluía al menos ese atributo. Así, por ejemplo, la frecuencia de 2,791 puntos de vista bajo la categoría "La CPR debe establecer el derecho a la educación de calidad", incluye el número de puntos de vista indicando "La CPR debe establecer el derecho a la educación de calidad", pero también aquellos señalando, entre otros, "La CPR debe establecer el derecho a la educación de calidad, gratuita y púbica." La mayoría de los puntos de vista analizados en la muestra contenían, de hecho, dos o más atributos.
} 
Tabla 2. Catálogo general de puntos-de-vista-tipo, con $x=1$ atributo

\begin{tabular}{|c|c|c|}
\hline Puntos-de-vista-tipo & Frecuencias & Porcentajes \\
\hline \multicolumn{3}{|l|}{ La CPR debe establecer el derecho a } \\
\hline la educación de calidad & 2,791 & 51.81 \\
\hline la educación gratuita & 1,975 & 36.66 \\
\hline la educación, garantizada por el Estado & 1,202 & 22.31 \\
\hline la educación pública & 634 & 11.77 \\
\hline $\begin{array}{l}\text { la educación sin discriminación/sin segregación/ integradora/ } \\
\text { inclusiva }\end{array}$ & 445 & 8.26 \\
\hline la educación laica & 287 & 5.33 \\
\hline la educación igualitaria & 257 & 4.77 \\
\hline la educación, con los siguientes contenidos curriculares... & 253 & 4.70 \\
\hline la educación integral & 251 & 4.66 \\
\hline la educación, entendido como un derecho humano & 243 & 4.51 \\
\hline la educación, donde el Estado cumpla un rol protagónico ${ }^{5}$ & 195 & 3.62 \\
\hline la educación sin fines de lucro & 190 & 3.53 \\
\hline la educación no mercantilizada & 177 & 3.29 \\
\hline la educación, con el siguiente sistema de provisión... & 132 & 2.45 \\
\hline la educación con desarrollo profesional docente o carrera docente & 130 & 2.41 \\
\hline la educación equitativa & 123 & 2.28 \\
\hline el acceso a la educación (sin mención a otros atributos) ${ }^{6}$ & 117 & 2.17 \\
\hline la educación, entendido como un derecho social ${ }^{7}$ & 113 & 2.10 \\
\hline la educación, complementado por la libertad de enseñanza & 93 & 1.73 \\
\hline la educación pluralista & 80 & 1.49 \\
\hline la educación, fortaleciendo la educación pública & 78 & 1.45 \\
\hline la educación, perfilada a lo que el país necesita & 63 & 1.17 \\
\hline la educación democrática & 59 & 1.10 \\
\hline la educación, no competitiva o menos competitiva ${ }^{8}$ & 59 & 1.10 \\
\hline la educación multicultural y/o intercultural & 44 & 0.82 \\
\hline
\end{tabular}

5 Dentro de esta categoría se incluyeron también expresiones tales como: "donde el estado cumpla el rol de Estado docente", "no al Estado Subsidiario", "derecho preferente del Estado de educar a los hijos."

6 Punto de vista tipo en el que los participantes definen el derecho a la educación sólo como derecho al acceso a la educación. Un total de 892 puntos de vista también mencionaron el derecho al acceso a la educación, pero en relación a otros atributos: por ejemplo, derecho al acceso a la educación gratuita y de calidad.

7 Es importante notar que aquí se contabilizan sólo los enunciados con el contenido proposicional "la educación es un derecho social" que cumplen la función de punto de vista. Es decir, no se contabilizan aquellos enunciados que definen la educación como un derecho social, pero cuya función es argumentativa (por ejemplo, en el enunciado “La educación debe estar consagrada en la Constitución, porque es un derecho social"). La misma observación se aplica a los fundamentos que definen la educación como derecho humano. Por lo tanto, los porcentajes en ambos casos no reflejan el total de veces que los participantes comprendieron el derecho a la educación como un "derecho social" o un "derecho humano."

8 Dentro de esta categoría se incluyeron también expresiones tales como: "educación no o menos individualista", "que promueva la colaboración/ cooperación/ vida en comunidad/ solidaridad", "educación entendida como un bien común o colectivo." 


\begin{tabular}{lcc}
\hline \multicolumn{1}{c}{ Puntos-de-vista-tipo } & Frecuencias & Porcentajes \\
\hline \multicolumn{1}{c}{ La CPR debe establecer el derecho a } & 36 & 0.67 \\
\hline la educación libre & 36 & 0.67 \\
la educación descentralizada & 34 & 0.63 \\
la educación desmunicipalizada & 33 & 0.61 \\
la educación, respetuosa de los intereses locales & 31 & 0.58 \\
la educación, la cual debe ser obligatoria & 25 & 0.46 \\
la educación, modificando o eliminando el sistema de evaluación & 17 & 0.32 \\
estandarizada & 15 & 0.28 \\
la educación, donde el Estado cumpla un rol secundario ${ }^{9}$ & 5 & 0.09 \\
la educación sin selección escolar & 3 & 0.06 \\
la educación sin copago & 2 & \\
la educación, el cual debe ser garantizado o asegurado por el Estado, \\
$\begin{array}{l}\text { a través de la acción de protección/ justiciable en los tribunales } \\
\text { la educación, donde se permita el lucro, pero regulado }\end{array}$ & 2 & 0.04 \\
\hline Total de puntos de vista extraídos de la muestra & 5,387 & \\
\hline
\end{tabular}

Las tablas 3 y 4, por otra parte, contienen puntos-de-vista-tipo con más de un atributo. Los puntos-de-vista-tipo recogidos en ambas tablas aportan información respecto a nudos controversiales en el discurso de la élite. Tal es el caso de la relación entre gratuidad y calidad, entre gratuidad y libertad de enseñanza, y entre gratuidad y educación particular: ${ }^{10}$

Tabla 3. Catálogos de puntos-de-vista-tipo, con $x>1$ atributo. Gratuidad y calidad.

\begin{tabular}{lrr}
\hline \multicolumn{1}{c}{ Puntos-de-vista-tipo } & Frecuencias & Porcentajes \\
\hline \multicolumn{1}{c}{ La CPR debe establecer el derecho a } & & \\
\hline la educación gratuita y de calidad & 1,636 & 30.37 \\
la educación de calidad (sin mención a la gratuidad) & 1,155 & 21.44 \\
la educación gratuita (sin mención a la calidad) & 339 & 6.29 \\
\hline Total de puntos de vista extraídos de la muestra & 5,387 & \\
\hline
\end{tabular}

9 Dentro de esta categoría se incluyeron también expresiones tales como: "donde el estado cumpla un rol subsidiario", "donde la principal responsabilidad recae en los padres/ la familia/organizaciones intermedias", "derecho preferente de los padres de educar a los hijos."

10 No está quizás demás señalar que la codificación realizada es tal que permite formular otras preguntas al material codificado, según el interés del investigador. Es decir, permite identificar nuevas asociaciones entre dos o más atributos. 
Tabla 4. Catálogo de puntos-de-vista-tipo, con $x>1$ atributo. Gratuidad, libertad de enseñanza y educación particular.

\begin{tabular}{lrr}
\hline \multicolumn{1}{c}{ Puntos-de-vista-tipo } & Frecuencias & Porcentajes \\
\hline \multicolumn{1}{c}{ La CPR debe establecer el derecho a } & & \\
\hline $\begin{array}{l}\text { la educación gratuita (sin mención a la necesidad de permitir la edu- } \\
\text { cación particular) }\end{array}$ & 1,943 & 99.41 \\
$\begin{array}{l}\text { la educación gratuita (sin mención a la libertad de enseñanza) } \\
\begin{array}{l}\text { la educación gratuita, pero acompañado de la libertad de enseñanza } \\
\text { la educación gratuita, pero permitiendo que existan proyectos de } \\
\text { educación particulares }\end{array}\end{array}$ & 1,935 & 99.26 \\
\hline Total de puntos de vista extraídos de la muestra & 30 & 0.74 \\
\hline
\end{tabular}

Además de analizar los puntos de vista, realizamos un análisis de los sub-puntos-de-vista presentes en la muestra, categorizándolos también en tipos. Un sub-punto de vista aporta información adicional relativa a uno de los atributos que determina al derecho a la educación en un punto de vista. Así, un análisis de los sub-puntos de vista nos permite conocer la opinión que tiene la ciudadanía frente a temas tan relevantes como: el tipo y nivel educativo en el que se debe implementar la gratuidad; los tipos de discriminación y segregación educativas que la ciudadanía reconoce y que espera que el derecho a la educación modere o elimine; los instrumentos que proponen para el fortalecimiento de la educación pública; qué significado atribuyen a la libertad de enseñanza; cuál es el sistema de provisión de educación de preferencia; y cuáles son los contenidos curriculares mínimos para una educación de calidad. Las tablas 5 a la 10 sintetizan los sub-puntos-de-vista tipo extraídos de la muestra y sus frecuencias:

Tabla 5. Catálogo de sub-puntos-de-vista-tipo. Tipos y niveles de gratuidad.

\begin{tabular}{|c|c|c|}
\hline Sub-puntos-de-vista-tipo & Frecuencias & Porcentajes \\
\hline \multicolumn{3}{|c|}{ La CPR debe establecer el derecho a la educación gratuita } \\
\hline \multicolumn{3}{|l|}{ Tipos de gratuidad $^{11}$} \\
\hline sin especificar tipo & 1,207 & 60.93 \\
\hline universal & 698 & 35.23 \\
\hline $\begin{array}{l}\text { focalizada en quienes más lo necesitan/ proporcional a las necesida- } \\
\text { des }\end{array}$ & 50 & 2.52 \\
\hline conforme al mérito & 18 & 0.91 \\
\hline mediante financiamiento a la demanda/ subvención a las familias & 8 & 0.40 \\
\hline Total de puntos de vista que mencionan "educación gratuita" & 1,975 & \\
\hline Total de menciones a la "educación gratuita" & 1,981 & \\
\hline
\end{tabular}

11 Tipo de gratuidad es una categoría que contiene ítems no-excluyentes. Por ejemplo, algunos ELA planteaban que la gratuidad debería estar focalizada en quienes más lo necesitan y, además, distribuirse dentro del grupo objetivo, conforme al mérito. 
Sub-puntos-de-vista-tipo

Frecuencias Porcentajes

La CPR debe establecer el derecho a la educación gratuita

Niveles de gratuidad

\begin{tabular}{lrr}
\hline en nivel sin especificar & 1,502 & 76.05 \\
en todos los niveles (al menos, básica a superior) & 364 & 18.38 \\
en el nivel básico & 24 & 1.21 \\
en el nivel medio & 19 & 0.96 \\
en el nivel superior & 19 & 0.96 \\
en el nivel escolar (básico y medio) & 18 & 0.91 \\
en el nivel preescolar & 11 & 0.56 \\
en el nivel preescolar y básico & 10 & 0.50 \\
en el nivel preescolar y escolar & 7 & 0.35 \\
en el nivel medio y superior & 1 & 0.05 \\
\hline Total de puntos de vista que mencionan "educación gratuita" & 1,975 & \\
\hline
\end{tabular}

Tabla 6. Catálogo de sub-puntos-de-vista-tipo. Tipos de discriminación y segregación educativas existentes, y que el derecho a la educación debiese eliminar.

\begin{tabular}{|c|c|c|}
\hline Puntos-de-vista-tipo & Frecuencias & Porcentajes \\
\hline \multicolumn{3}{|c|}{ La CPR debe establecer el derecho a la educación sin discriminación/segregación } \\
\hline \multicolumn{3}{|l|}{ Tipos de discriminación y/o segregación ${ }^{12}$} \\
\hline sin especificar tipo & 292 & 57.25 \\
\hline socio-económica & 81 & 15.88 \\
\hline por credo religioso & 77 & 15.10 \\
\hline por capacidades & 41 & 8.04 \\
\hline por motivos de género & 11 & 2.16 \\
\hline étnico-racial & 8 & 1.60 \\
\hline $\begin{array}{l}\text { Total de puntos de vista que mencionan "educación sin discrimina- } \\
\text { ción/segregación" }\end{array}$ & 445 & \\
\hline Total de menciones a "sin discriminación/segregación" & 510 & \\
\hline
\end{tabular}


Tabla 7. Catálogo de sub-puntos-de-vista-tipo. Instrumentos para el fortalecimiento de la educación pública.

\begin{tabular}{|c|c|c|}
\hline Puntos-de-vista-tipo & Frecuencias & Porcentajes \\
\hline \multicolumn{3}{|c|}{ La CPR debe establecer el derecho a la educación, fortaleciendo la educación pública } \\
\hline \multicolumn{3}{|l|}{ Instrumentos para fortalecer la educación pública ${ }^{13}$} \\
\hline sin especificar el medio & 48 & 60.76 \\
\hline $\begin{array}{l}\text { con recursos estatales destinados sólo a la educación pública/ po- } \\
\text { niendo fin a la educación particular subvencionada }\end{array}$ & 19 & 24.05 \\
\hline con más recursos para la educación pública & 8 & 10.13 \\
\hline $\begin{array}{l}\text { con financiamiento estable de la educación pública/ poniendo fin al } \\
\text { sistema de voucher educativo }\end{array}$ & 4 & 5.06 \\
\hline $\begin{array}{l}\text { Total de puntos de vista que mencionan "fortaleciendo la educación } \\
\text { pública" }\end{array}$ & 78 & \\
\hline Total de menciones a "fortaleciendo la educación pública" & 79 & \\
\hline
\end{tabular}

Tabla 8. Catálogo de sub-puntos-de-vista-tipo. Significados de la libertad de enseñanza.

\begin{tabular}{lcc}
\hline \multicolumn{1}{c}{ Puntos-de-vista-tipo } & Frecuencias & Porcentajes \\
\hline \multicolumn{1}{c}{ La CPR debe establecer el derecho a la educación, complementado por la libertad de enseñanza } \\
\hline \multicolumn{1}{c}{ Significados de la libertad de enseñanza } & & \\
\hline $\begin{array}{l}\text { sin especificar significado } \\
\text { entendido como la libertad de los padres de escoger el establecimien- } \\
\text { to de enseñanza para sus hijos } \\
\text { entendido como la libertad de los establecimientos de establecer pro- }\end{array}$ & 19 & 60.22 \\
$\begin{array}{l}\text { yectos educativos diversos a los del Estado } \\
\text { entendido como la libertad de los padres de escoger el establecimien- } \\
\text { to de enseñanza para sus hijos y la libertad de los establecimientos de } \\
\text { establecer proyectos educativos diversos a los del Estado }\end{array}$ & 30.43 \\
\begin{tabular}{l} 
Total de puntos de vista que mencionan “libertad de enseñanza” \\
\hline
\end{tabular} & 36.13 \\
\hline
\end{tabular}

Tabla 9. Catálogo de sub-puntos-de-vista-tipo. Sistema de provisión de educación.

Puntos-de-vista-tipo

Frecuencias Porcentajes

La CPR debe establecer el derecho a la educación, con un sistema de provisión de educación:

\begin{tabular}{lrr}
\hline \multicolumn{4}{c}{ Sistema de provisión de educación } \\
\hline estatal & 62 & 46.97 \\
mixto & 49 & 37.12 \\
mixto, pero donde el Estado regule el sistema privado de educación & 21 & 15.91 \\
\hline Total de puntos de vista que mencionan "sistema de provisión" & 132 & \\
\hline
\end{tabular}

13 Instrumentos para fortalecer la educación púbica es una categoría que contiene ítems no-excluyentes. 
Tabla 10. Catálogo de sub-puntos-de-vista-tipo. Contenidos curriculares.

\begin{tabular}{lcr}
\hline \multicolumn{1}{c}{ Puntos-de-vista-tipo } & Frecuencias & Porcentajes \\
\hline \multicolumn{4}{c}{ Contenidos curriculares ${ }^{14}$} \\
\hline \multicolumn{4}{c}{ La CPR debe establecer el derecho a la educación, con los siguientes contenidos curriculares: } \\
\hline $\begin{array}{l}\text { deben incluir educación cívica/ formación ciudadana/ promover } \\
\text { derechos y principios constitucionales }\end{array}$ & 163 & 53.09 \\
deben incluir principios y valores & 67 & 21.82 \\
deben incluir historia, lengua y/o cultura de los pueblos originarios & 26 & 8.47 \\
debe incluir respeto y cuidado del medio ambiente & 25 & 8.14 \\
debe incluir educación sexual & 15 & 4.89 \\
debe incluir la enseñanza de DD.HH & 10 & 3.26 \\
debe incluir educación económica & 1 & 0.33 \\
Total de puntos de vista que mencionan “contenidos curriculares" & 253 & \\
\hline Total de menciones a “contenidos curriculares" & 307 & \\
\hline
\end{tabular}

\section{PODER IDEACIONAL EN EL DEBATE EDUCACIONAL: EXPERTOS, MOVIMIENTOS Y ELA}

El debate de los ELA ocurre en 2016, a consecuencia de un proceso participativo en busca de un cambio constitucional integral, el cual había sido impulsado desde hace años por la irrupción de movimientos sociales, donde se destacaba el movimiento estudiantil demandando una educación pública, gratuita y de calidad. De esa manera, era esperable que hubiese un reflejo en las opiniones que se vertieran en los diálogos ciudadanos de los puntos de vista del movimiento social.

En efecto, si bien es posible apreciar en el análisis cualitativo de los ELA la presencia de una amplia gama de puntos de vista que recogen las más diversas posturas del discurso ideacional de las élites, nuestro análisis cuantitativo muestra que algunos de estos contenidos tienen una frecuencia significativamente mayor.

Así, y en primer lugar, es clara una identificación que hicieron los ELA de los contenidos del derecho a la educación con la calidad $(51.81 \%)$ y la gratuidad $(36.66 \%)$. Como se ve en la tabla 2 , plantean que el derecho a la educación no se realiza principalmente con el acceso $(2.17 \%)$, en línea con los planteamientos de un grupo de expertos en la educación y que luego será defendida por los movimientos estudiantiles en 2006 y 2011. Lo anterior se ve reforzado por la asunción que debe ser el Estado el que garantice o asegure el derecho a la educación $(22.31 \%)$, y que se debe garantizar el derecho a una educación pública $(11.70 \%)$, que debe ser integradora, inclusiva, sin discriminación y segregación (8.26\%). 
Asimismo, en cuanto a la determinación de la gratuidad existe consistencia en los ELA, según se aprecia en la tabla 5, en su atribución respecto a todos los niveles del sistema educacional (18.38\%), y en su característica de ser universal (35.23\%). El porcentaje de menciones a la universalidad de la gratuidad en educación es notoriamente mayor, si se calcula sobre el total de los puntos de vista que especificaron a qué tipo de gratuidad se refieren, dejando de lado aquellos puntos de vista que defienden la gratuidad, pero sin especificar su tipo $(90.18 \%)$. Otro tanto ocurre con la idea de que la gratuidad debe operar en todos los niveles $(76.96 \%)$.

Por su parte, como se muestra en las tablas 2 y 4, la libertad de enseñanza no aparece en la deliberación de los ELA al mismo nivel que la gratuidad, o siquiera como un elemento relevante del derecho a la educación. Más bien una cantidad menor indica que el derecho a la educación debe ser complementado por la libertad de enseñanza (1.73\%). En este sentido, los ELA parecen distanciarse de aquellos que defienden la libertad de enseñanza como un derecho equivalente a la educación.

Los puntos de vista que se pronuncian abiertamente respecto al tipo de sistema de provisión educacional son pocos $(2.45 \%)$. No obstante, dentro de ese pequeño grupo de puntos de vista se manifiesta, como indica la tabla 9 , una preferencia significativa por un sistema estatal (46.97\%), seguido por un sistema mixto $(37.12 \%)$ y un sistema mixto, pero donde el Estado regule el sistema privado de educación (15.91\%) (aunque en total el sistema mixto sume 53.03\%). Son pocos también los puntos de vista que se refieren directamente al rol que debe desempeñar el Estado en la educación (3.94\%). Sin embargo, conforme a la tabla 2, en ese pequeño universo de puntos de vista es clara la preferencia por un modelo educativo donde el Estado cumpla un rol protagónico (92\%), en lugar de subsidiario (8\%). Asimismo, son escasos los puntos de vista que mencionan el lucro en la educación (3.57\%), pero es notoria la preferencia por un derecho a la educación sin fines de lucro (99\%) por sobre el lucro regulado (1\%), destacando además la ausencia de puntos de vista defendiendo la educación con fines de lucro (0\%).

Ahora bien, esta sintonía de los ELA con el punto de vista que se ha hecho predominante en el debate de los emprendedores de políticas públicas previo debe ser matizada. Existe una visión predominante en los ELA sobre que el contenido más importante del derecho a la educación es la calidad (51.81\%); sin embargo, como da cuenta la tabla 3, un número menor de puntos de vista vincula directamente calidad y gratuidad (30.37\%), y hay un $21 \%$ que se refiere a la calidad sin vincularla a la gratuidad. Asimismo, como se ha visto, ni el derecho a la educación pública ni el rol del Estado como garante del derecho a la educación alcanzan un porcentaje cercano al 50\%, como sí ocurre en el caso del derecho a la educación de calidad. Esto parece sugerir que si bien existe una sintonía importante de la deliberación de los ELA con los significados del derecho a la educación que han sido predominantes en el debate de las élites, no se expresa una recepción con la misma intensidad de las ideas que sirven 
de imanes de coalición a favor de la educación gratuita, fuertemente garantizada por el Estado y orientada hacia la educación pública y que se aparta de la garantía mediante estándares sobre una provisión privada. Si bien es claro que, tratándose los "fundamentos" de respuestas a preguntas abiertas, la no mención de una categoría no implica que se asuma la posición contraria (esto es, no mencionar la gratuidad no implica estar en contra de ella), su ausencia sí sugiere una decisión -consciente o no- de no darle la misma relevancia que aquello que sí se menciona en un encuentro local.

Junto con lo anterior, hay contenidos normativos, vinculados al derecho a la educación, que los ELA mencionan y que, sin embargo, no están en el debate de los emprendedores de políticas públicas, o si lo están, es sólo de forma marginal. Así, es notable que el carácter laico de la educación sea el $6^{\circ}$ atributo más mencionado (5.33\%) por los ELA en la tabla 2, y que entre los tipos de discriminación y/o segregación más mencionados de la tabla 6 este aquella basada en el credo religioso $(15.10 \%)$ no muy lejos de la socio-económica que ocupa el $1^{\circ}$ lugar entre las discriminaciones y/o segregaciones (15.88\%). En el mismo sentido, la discriminación y segregación por capacidades también es mencionada (8.04\%), en circunstancias que en el debate de las élites ha sido un tema poco visibilizado. En la misma línea, se menciona la necesidad de una educación de carácter multicultural y/o intercultural (0.82\%). Por último, los ELA dan cuenta de dos preocupaciones presentes en el debate de las élites de modo más bien marginal, aunque es discutible si estos son contenidos propios de un debate constitucional: la cuestión de la definición de los contenidos curriculares (4.7\%) y la necesidad de desarrollar un sistema educativo basado en la cooperación, antes que en la competencia (1.1\%).

El poder ideacional que organizaron los expertos que cuestionaban las "reformas basadas en estándares" ha logrado no sólo conformar marcos de significado para la articulación de movimientos sociales en torno al derecho a la educación, sino que se expresa en la ciudadanía y puede así aparecer en procesos de deliberación pública como los ELA. Con ello, podemos constatar que los movimientos sociales de la segunda fase del debate reciente amplificaron en la opinión pública los contenidos que los expertos referían a la educación entendida como un derecho. Calidad, gratuidad, garantía estatal, inclusividad son atributos que debe tener el derecho a la educación, según relevan los ELA. Como tales han sido eficaces "imanes de coalición", lo que explica la influencia efectiva en las políticas públicas que se han decidido e implementado con esos contenidos.

Pero la ciudadanía que se manifestó en los ELA, si bien apoyaba por cierta mayoría de manera consistente ese discurso, tampoco se deja encuadrar por completo dentro del alcance de ese poder ideacional. Como ya indicamos, esto no implica que existan porciones de la ciudadanía convencidas de la otra coalición discursiva, y que reflejen con claridad un poder ideacional de quienes defienden un derecho autónomo de la libertad de enseñanza para proveedores privados de educación. 
Más bien, el poder ideacional del discurso en pos de la educación pública no logra el apoyo más relevante en torno a la gratuidad, sino sólo en cuanto a la relevancia de la calidad. Con ello, relega completamente el enfoque de las reformas educativas que se emprendieron durante los primeros gobiernos de la Concertación, destinadas a asegurar el acceso, incrementando la cobertura del sistema educativo. Sin embargo, el concepto de calidad puede quedar abierto a ser satisfecho por una garantía estatal que opere mediante la regulación de sector privado mediante estándares, o bien por medio de un fortalecimiento de la educación pública.

En este sentido, la calidad de la educación podría considerarse un significante equívoco, que puede asociarse al discurso del derecho a la educación gratuita, pública y de calidad, pero que siempre puede ser retomado desde una perspectiva de una educación provista por privados y asegurada por estándares.

También hay algunos temas emergentes en el debate ciudadano, tales como el laicismo de la educación, lo cual también da cuenta de que es incorrecto asumir de antemano que los significados en la ciudadanía son mero reflejo del poder ideacional de las élites.

\section{CONCLUSIONES}

La posibilidad de que exista una deliberación ciudadana que sea registrada y sistematizada, nos permite tener voces en el debate constitucional que antes no eran consideradas. Esto no significa que tendrán puntos de vista absolutamente diferentes de los que ya existían en el debate de las élites, expertos y movimientos.

En un punto de larga trayectoria del debate en el sistema político chileno, como es la educación, en las décadas recientes la discusión sobre su significado como derecho constitucional ha sido un eje estructurante de la política. Esta situación fue preparada por una fructífera reflexión entre expertos en educación, donde se plantearon las ideas que posteriormente congregaron a importantes actores colectivos como los movimientos estudiantiles.

El poder ideacional desarrollado por los expertos en lo que hemos identificado como una primera etapa desde el retorno a la democracia, fue capaz de generar marcos de significado que han congregado coaliciones no usuales, donde los movimientos sociales van, en una segunda etapa, a amplificar y elevar un entendimiento del derecho a la educación. Esto posibilitará una tercera etapa donde se entraría en una discusión propiamente iusconstitutional del derecho a la educación.

Precisamente, en esa última etapa es donde se hace posible una discusión ciudadana como la de los ELA. La sistematización alternativa que realizamos de sus actas nos permitió visualizar de manera más clara los puntos de vista de los 
ciudadanos participantes y establecer una relación con los puntos de vista del debate de los expertos y los movimientos sociales.

El debate de los ELA ha expresado su receptividad de las ideas de élites, confirmando el poder ideacional de lo que ha venido siendo la coalición discursiva predominante a favor de un derecho constitucional de la educación orientada hacia la educación pública, gratuita y de calidad. Sin embargo, no constituye un reflejo completo de dichos marcos de significado, puesto que la demanda de calidad puede cumplir un rol equívoco a lo menos, donde podría ser satisfecha por una educación con orientación a lo público, o bien por una educación provista por privados y garantizada por estándares.

En este sentido, pareciera que la ciudadanía que participó en los encuentros eleva a jerarquía constitucional una directriz que promueva la calidad y, en cambio, se divide entre quienes subordinan su realización a una esfera puramente legal o de políticas públicas, y otros que quieren asegurarla constitucionalmente para retrotraer su mercantilización. Si esto fuera así, se podría decir que el proceso participativo promovido por Bachelet aporta una clara definición en el escenario de una nueva constitución. Con esto, por otra parte, la experiencia chilena también aportaría en el debate comparado del reemplazo constitucional, ya que pone en cuestión la tesis sostenida Ackerman (1991), que duda del aporte que la ciudadanía en la elaboración de contenidos en los procesos constituyentes.

Las tareas de sistematizaciones de los debates ciudadanos sobre conceptos complejos como los derechos constitucionales permiten revelar cómo la ciudadanía no se sujeta necesariamente al poder ideacional de las élites en sus diversas formas, e incluso puede aparecer un poder ideacional ciudadano, visibilizando nuevas problemáticas y propuestas.

En la medida que los procesos participativos que van de la mano de procesos de reemplazo constitucional generen sistematizaciones serias, puede indagarse más profundamente en el real aporte que significan estos procesos para el debate constitucional. La poca relevancia que hoy se le asigna ha ido de la mano de estudios que no ahondan en los debates específicos generados por la ciudadanía.

\section{REFERENCIAS}

Ackerman, Bruce. 1991. We the people: foundations. Cambridge: Harvard University Press.

Acuña, Violeta. 2016. "A 10 años del Movimiento Estudiantil Chileno, reflexiones sobre sus protagonistas." Altre Modernita 4: 161-175.

Almonacid, Claudio. 2004. "Un cuasi mercado educacional: la escuela privada subvencionada en Chile." Revista de Educación 333: 165-196.

Atria, Fernando. 2010. “Qué educación es pública?” En Ecos de la Revolución Pingüina, Avances, debates y silencios en la reforma educacional, editado por Bellei, Cristián, Daniel Contreras y Juan Pablo Valenzuela. Santiago: Universidad de Chile y UNICEF. 
Atria, Fernando. 2014. Derechos sociales y educación: un nuevo paradigma de lo público. Santiago: LOM.

Atria, Fernando, Guillermo Larraín, José Miguel Benavente, Javier Couso y Alfredo Joignant. 2013. El Otro Modelo, del Orden Neoliberal al Régimen de lo Público. Santiago: Debate.

Azócar, Carlos. 2014. "La tinta sobre el movimiento: revisión y propuesta de clasificación de la literatura sobre el movimiento estudiantil chileno (2011-2014) a la luz del nuevo escenario político y su crisis" Anuari del Conflicte Social 4: 202-228.

Béland, Daniel y Robert Cox. 2016. "Ideas as coalition magnets: coalition building, policy entrepreneurs, and power relations." Journal of European Public Policy 23 (3): 428-445.

Bellei, Cristián. 2005. The Private-Public School Controversy: The Case of Chile. PEPG 05-13, Program on Education Policy and Governance, Harvard University.

Bellei, Cristián. 2011. "La educación pública que Chile necesita." En El Chile que se viene, editado por Lagos, Ricardo y Oscar Landerretche. Santiago: FDD y Editorial Catalonia.

Bellei, Cristián. 2015. El Gran Experimento, Mercado y Privatización de la Educación Chilena. Santiago: LOM.

Bellei, Cristián y Cristian Cabalin. 2013. “Chilean student movements: Sustained struggle to transform a market-oriented educational system." Current Issues in Comparative Education 15 (2): 108-123.

Bellei, Cristián, Dante Contreras y Juan Pablo Valenzuela. 2010. “Viejos dilemas y nuevas propuestas en la política educacional chilena." En Ecos de la Revolución Pingüina, Avances, debates y silencios en la reforma educacional, editado por Bellei, Cristián y Dante Contreras, Daniel, Juan Pablo Valenzuela. Santiago: Universidad de Chile y UNICEF.

Bellei, Cristián y Luz María Pérez. 2000. Tensión entre derecho a la educación y libertad de enseñanza. Santiago: UNICEF.

Bourdieu, Pierre. 1989. La Noblesse d'État. Grandes écoles et esprit de corps. Paris: Les Éditions de Minuit.

Cea, José Luis. 2013. Derecho Constitucional Chileno. Tomo II. 2da edición actualizada. Santiago: Ediciones Universidad Católica.

Comité de Sistematización. 2016. Encuentros Locales Autoconvocados. Reporte de sistematización de los fundamentos asociados a los siete conceptos más mencionados del eje "Derechos". Recuperado el 8 de enero de 2017 de www.sistematizaciónconstitucional.cl

Comité de Sistematización. 2017. Informe Ejecutivo: Sistematización de la etapa participativa del proceso constituyente abierto a la ciudadanía. Recuperado el 8 de enero de $2017 \mathrm{de} \mathrm{http:/} \mathrm{/}$ archivospresidenciales.archivonacional.cl/index.php/informe-ejecutivo-sistematizacion-de-la-etapa-participativa-del-proceso-constituyente-abierto-la-ciudadania

Consejo Asesor Presidencial para la Calidad de la Educación. 2006. Informe Final. Santiago: Gobierno de Chile.

Cousin, Bruno, Shamus Khan y Ashley Mears. 2018. Theoretical and methodological pathways for research on elites. Socio-Economic Review 16(2): 225-249.

Cox, Cristian. 2005. La Políticas educacionales de Chile en las últimas dos décadas del siglo XX. En Políticas educacionales en el cambio de siglo. La reforma del sistema escolar de Chile, editado por Cristian Cox. Santiago: Editorial Universitaria.

Cox, Cristian. 2012. "Política y Políticas Educacionales en Chile 1990-2010." Revista Uruguaya de Ciencia Política 21(1): 13-42.

Donoso, Sofía. 2013. "Dynamics of Change in Chile: Explaining the Emergence of the 2006 Pingüino Movement." Journal of Latin American Studies 45(1): 1-29.

Domhoff, Gillian. 1967. Who Rules America? Englewood Cliffs: Prentice-Hall.

Fernández Labbé, Juan. 2016. Protesta social, consecuencias y subjetividades políticas: la huella del movimiento estudiantil chileno del año 2011. Tesis Doctoral. Madrid: Universidad Complutense de Madrid.

Fischer, Frank y John Forester. 1993. The Argumentative Turn in Policy Analysis and Planning. London: Duke University Press.

García-Huidobro, Juan Eduardo. 2004. “A modo de síntesis: Políticas Educativas y Equidad en Chile." En Políticas Educativas y Equidad, Reflexiones del Seminario Internacional, edi- 
tado por Juan Eduardo García-Huidobro. Santiago: Ford Foundation, UNESCO, UNICEF y U. Alberto Hurtado.

Ghai, Yash. 2006. The Role of Constituent Assemblies in Constitution Making. International IDEA. Recuperado el 25 de febrero de 2019 http://constitutionnet.org/sites/default/files/2017-08/the_role_of_constituent_assemblies_-_final_yg_-_200606.pdf

Gluck, Jason y Brendan Ballou. 2014. New Technologies for Constitution Making. USIP. Recuperado el 25 de febrero de 2019 de https:/ /www.usip.org/sites/default/files/SR343_ New-Technologies-for-Constitution-Making.pdf

Hartmann, Michael. 2006. The Sociology of Elites. New York: Routledge.

Insunza, Jorge. 2009. La construcción del derecho a la educación y la institucionalidad educativa en Chile: antecedentes para una polémica de 200 años. Santiago: OPECH.

Jackson, Giorgio. 2013. El país que soñamos. Santiago: Debate.

Larroulet, Cristian y Jacinto Gorosabel. 2015. La Educación en la Encrucijada: ¿Estado Docente o Sociedad Docente? Santiago: Universidad del Desarrollo y RIL.

Mills, Charles Wright. 1956. The Power Elite. New York: Oxford University Press.

Orellana, Víctor. 2012. "Sobre el malestar social con la educación y la energía del movimiento social. El primer paso del Chile del Siglo XXI". En Del Río, M. [Ed.] Es la educación, estúpido! Santiago: Ariel.

Partlett, William. 2012. "The Dangers of Popular Constitution-Making." Brooklyn Journal of International Law. Recuperado el 25 de febrero de 2019 de http://dx.doi. org/10.2139/ssrn.1924958

Peña, Carlos . 2015. "Escuela y vida cívica", pp. 25-50. En Cox, C., \& Castillo, J. C (Eds). Aprendizaje de la ciudadanía: Contextos, experiencias y resultados, Santiago: Ediciones UC.

Picazo, María Inés. 2010. “La metamorfosis de la regulación pública en la educación escolar en Chile: hacia un estado post-neoliberal." Revista Pensamiento Educativo 46(1): 63-91.

Picazo, María Inés. 2013. Las políticas escolares de la Concertación durante la transición democrática. Santiago: Ediciones Universidad Diego Portales.

Putnam, Robert. 1977. "Elite Transformation in Advanced Industrial Societies: An Empirical Assessment of the Theory of Technocracy." Comparative Political Studies 10(3): 383-411.

Ruiz-Tagle, Pablo. 2010. "Apuntes para la reforma educacional." En Ecos de la Revolución Pingüina, Avances, debates y silencios en la reforma educacional", editado por Cristián Bellei, Daniel Contreras y Juan Pablo Valenzuela. Santiago: Universidad de Chile y UNICEF.

Saati, Abrak. 2015. The Participation Myth, Outcomes of participatory constitution building processes on democracy. Umeå: Umeå University.

Salazar, José y Peodair Leihy. 2013. "El Manual Invisible. Tres décadas de políticas de educación superior en Chile (1980-2010)." Archivos Analíticos de Políticas Públicas 21(34): 1-35.

San Francisco, Alejandro. 1992. "Jaime Guzmán y el Principio de Subsidiaridad Educacional en la Constitución de 1980." Revista Chilena de Derecho 19(3): 527-548.

Soto, Francisco y Yanina Welp. 2017. Los 'diálogos ciudadanos'. Chile ante el giro deliberativo. Santiago: LOM.

Treviño, Ernesto. 2018. "Diagnóstico del sistema escolar: las reformas educativas 2014-2017." En Ideas en educación II, definiciones en Tiempos de Cambio, editado por Ignacio Sánchez. Santiago: Ediciones Universidad Católica.

Treviño, Ernesto, Juan Valenzuela y Cristóbal Villalobos. 2014. Segregación académica y socioeconómica al interior de la escuela en Chile. Santiago: Fondo de Investigación y Desarrollo en Educación - FONIDE.

Villalobos, Cristóbal, Alejandro Carrasco, Ernesto Treviño y Ignacio Wyman. 2019. "La Puesta en marcha de la nueva educación pública: relevancia, impacto y sustentabilidad." En De la reforma a la transformación capacidad, innovaciones y regulación de la educación chilena, editado por Alejandro Carrasco y Luis Flores. Santiago: Ediciones Universidad Católica. 
Villalobos, Cristóbal y María Quaresma. 2015. “Sistema escolar chileno: características y consecuencias de un modelo orientado al mercado." Convergencia Revista de Ciencias Sociales 69: 63-84.

Vivanco, Ángela. 2007. “Derecho a la educación y libertad de enseñanza: un aparente conflicto y sus efectos sobre una proposición normativa en Chile." Temas de la Agenda Pública 2(8). Santiago: Universidad Católica.

Welp, Yanina y Francisco Soto. 2019. "Más allá de modas y cortinas de humo: la deliberación ciudadana en cambios constitucionales." Revista Española de Ciencia Política 50: 13-41.

Woods, Michael. 1998. "Rethinking Élites: Networks, Space, and Local Politics." Environment and Planning A: Economy and Space 30(12): 2101-2119.

Recibido: 11 de agosto de 2019

Aceptado: 13 de septiembre de 2020

Constanza Ihnen Jory es Licenciada en Letras por la Pontificia Universidad Católica de Chile y Doctora en Teoría de la Argumentación, Retórica y Filosofía del Lenguaje por la Universidad de Ámsterdam. Actualmente es Profesora Asistente del Instituto de Argumentación de la Facultad de Derecho de la Universidad de Chile. Correo electrónico: cihnen@derecho.uchile.cl

Salvador Millaleo Hernández es abogado por la Universidad de Chile, Doctor en Sociología por la Universidad de Bielefeld, Alemania. Actualmente es investigador del Centro de Derechos Humanos de la Facultad de Derecho de la Universidad de Chile. Correo electrónico: smillaleo@derecho.uchile.cl

Francisco Soto Barrientos es abogado, Magister por la Universidad Diego Portales y Doctor en Derecho por la Universidad de Barcelona. Actualmente es Director de Investigación de la Facultad de Derecho Universidad de Chile, donde se encuentra adscrito al Departamento de Derecho Público, en calidad de profesor asociado. Correo electrónico: fsoto@derecho.uchile.cl 